LEAL, D.S.L. e GOMES, L.A. Hemivértebra em cães e gatos. PUBVET, Londrina, V. 5, N. 32, Ed. 179, Art. 1206, 2011.

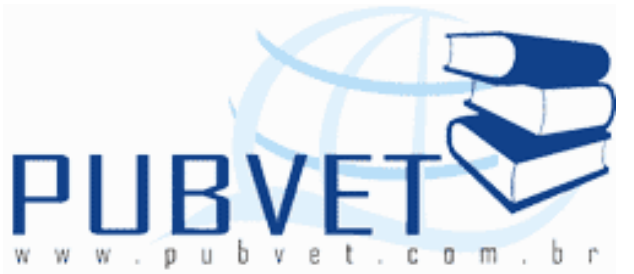

PUBVET, Publicações em Medicina Veterinária e Zootecnia.

\title{
Hemivértebra em cães e gatos
}

Deborah de Souza Leandro Leal ${ }^{1}$ e Lucas Alécio Gomes ${ }^{2}$

${ }^{1}$ Médica Veterinária Autônoma.

${ }^{2}$ Prof. Dr. Clínica Médica e Terapêutica de Pequenos Animais; Departamento de Medicina Veterinária; Universidade Federal de Mato Grosso do Sul - Campo Grande - MS.

\section{Resumo}

A hemivértebra é uma anomalia que na maioria das vezes é assintomática, entretanto, é a alteração vertebral congênita que mais frequentemente resulta em sinais neurológicos da medula espinhal. $O$ fato de ser na maioria dos casos um achado radiológico acidental faz com que esta enfermidade seja discutida de forma superficial, a despeito do quadro clínico neurológico grave com a progressão da doença. O objetivo deste trabalho é descrever as causas desta anomalia em cães e gatos, bem como ressaltar a patogenia, os sinais clínicos, os meios de diagnóstico e modalidades de tratamento.

Palavras-chave: cães; gatos; neurologia veterinária; hemivértebra.

\section{Hemivertebrae in dogs and cats}

\section{Abstract}

Hemivertebrae is an anomaly that most often is asymptomatic. However, it is the vertebral congenital disease that frequently most results in spinal cord 
LEAL, D.S.L. e GOMES, L.A. Hemivértebra em cães e gatos. PUBVET, Londrina, V. 5, N. 32, Ed. 179, Art. 1206, 2011.

neurological signs. In the majority of the cases this condition is a radiological accidental finding promotes commonly a superficial discussion of this disease, despite the severe neurological signs as the condition progresses. The aim of this article is describe the causes of this anomaly in dogs and cats and highlight the pathogenesis, clinical sings, diagnostic tools and treatment modalities.

Keywords: dogs; cats; veterinary neurology; hemivertebrae.

\section{INTRODUÇÃO}

Hemivértebra é uma anomalia congênita em que uma ou mais vértebras se apresentam em forma de cunha, podendo ocorrer alteração na direção de seu ápice que pode se apresentar inclinado dorsal, ventral ou lateralmente em relação ao eixo longitudinal do corpo (BAILEY \& MORGAN, 1992).

Esta anomalia surge em decorrência do desenvolvimento assimétrico ou falha nos centros de ossificação de uma ou mais vértebras, originando vértebras de comprimento mais curto ou outras deformidades (DONE et al, 1975).

Já foram relatadas em diversas raças de cães, porém ocorrem com mais frequência nas raças braquicefálicas de cauda enrolada como Buldogue Francês, Buldogue Inglês, Pug e Boston Terrier. As caudas-enroladas resultam de hemivértebras caudais (LeCOTEUR \& GRANDY, 2004). Em gatos é menos freqüente do que em cães e foi relatada na raça Manx (HAVLICEK, et al, 2008). Há relatos de hemivértebras em lobos (Canis Lupus) e pingüins (Spheniscus demersus) (RÄIKKONEN et al, 2005; BRADFORD et al, 2008).

Essa anomalia pode acometer qualquer vértebra, mas está mais comumente associada às torácicas (GRENN \& LINDO, 1969; LeCOTEUR \& GRANDY, 2004; RÄIKKONEN et al, 2005; BRADFORD et al, 2008; HAVLICEK et al, 2008) e lombares (LEÓN, 2009). Dentre estas a oitava vértebra torácica é a mais acometida pela deformidade (DONE, et al, 1975). 
LEAL, D.S.L. e GOMES, L.A. Hemivértebra em cães e gatos. PUBVET, Londrina, V. 5, N. 32, Ed. 179, Art. 1206, 2011.

Em Pointers Alemães de pêlo curto as hemivértebras torácicas são heranças autossômicas recessivas (KRAMER et al, 1982).

As deformidades vertebrais congênitas normalmente não apresentam sinais clínicos, porém a hemivértebra é a que mais comumente gera anormalidades neurológicas. Os sinais clínicos surgem quando a presença da hemivértebra gera instabilidade ou deformidade do canal vertebral ou compressão da medula ou raiz nervosa (BAILEY \& MORGAN, 1992).

Como muitos animais podem ter hemivértebras de forma subclínica, estas muitas vezes são achados radiológicos acidentais (LeCOTEUR \& GRANDY, 2004).

As hemivértebras podem causar angulação da coluna em graus variados (GRENN \& LINDO, 1969; ARAÚJO JÚNIOR et al, 2007; ARRIAGADA et al, 2009; PENHA et al, 2010). Em humanos as hemivértebras são a causa de $5 \%$ das angulações congênitas (McMASTER \& OHTSUKA, 1982).

Os animais sintomáticos devem ser submetidos à correção cirúrgica para melhoria da qualidade de vida (SEIM III, 2002, BAILEY \& MORGAN, 1992).

\section{REVISÃO DE LITERATURA}

\section{Anatomia vertebral}

A coluna vertebral dos carnívoros domésticos é composta por numerosos ossos irregulares e separados, as vértebras. Estão unidos de forma estável, porém não rígida e sua função é fortalecer o eixo do corpo, manutenção da postura e proteção da medula espinhal (DYCE, SACK \& WENSING, 2002).

A coluna vertebral dos cães e gatos é dividida em 5 partes: cervical, torácica, lombar, sacral e caudal. Via de regra o cão e o gato apresentam 7 vértebras cervicais, 13 torácicas, 7 lombares (podendo variar para 6), 3 sacrais e em torno de 20 vértebras caudais, sendo este número muito variável até mesmo dentro de uma mesma espécie (SISSON, 1986; DYCE, SACK \& WENSING, 2002). 
LEAL, D.S.L. e GOMES, L.A. Hemivértebra em cães e gatos. PUBVET, Londrina, V. 5, N. 32, Ed. 179, Art. 1206, 2011.

Uma vértebra típica é composta por um corpo maciço recoberto por um arco que delimita o forame vertebral que, com a justaposição das vértebras, formam o canal vertebral. O corpo é cilíndrico, dorsalmente achatado. Sua extremidade cranial é convexa e a caudal é côncava. O arco é composto de dois pedículos verticais e cada um deles emite uma projeção e estas se unem formando o anel em torno da medula espinhal. Na base de cada pedículo há um chanfro que se combina de modo a delinear os forames intervertebrais quando duas vértebras se articulam. Cada vértebra possui ainda processo dorsal ou espinhoso e processos transversos (DYCE, SACK \& WENSING, 2002).

\section{Desenvolvimento embrionário das vértebras}

As vértebras se formam a partir da região medial dos somitos denominada esclerótomo composto de mesênquima. No cão se formam cerca de 40 pares de somitos, os quatro primeiros pares originam estruturas do crânio e os demais se destinam à formação das vértebras em sentido craniocaudal. Cada esclerótomo possui duas áreas distintas, uma cranial com células mais esparsas que origina o corpo vertebral e outra caudal e mais densa que origina o arco vertebral, a associação destas duas populações de células forma o esboço de uma vértebra (Figura 1). Cada vértebra é formada por contribuições de dois somitos de cada lado, por isso é descrita como estrutura intersegmentar (NODEN \& LAHUNTA,1990).

No cão a ossificação das vértebras inicia na sexta semana de gestação e termina na vida adulta (NODEN \& LAHUNTA,1990), entre os sete e os 14 meses de idade nos cães (DYCE, SACK \& WENSING, 2002) e entre cinco a nove meses no gatos (HAVLICEK, et al, 2008). 
LEAL, D.S.L. e GOMES, L.A. Hemivértebra em cães e gatos. PUBVET, Londrina, V. 5, N. 32, Ed. 179, Art. 1206, 2011.

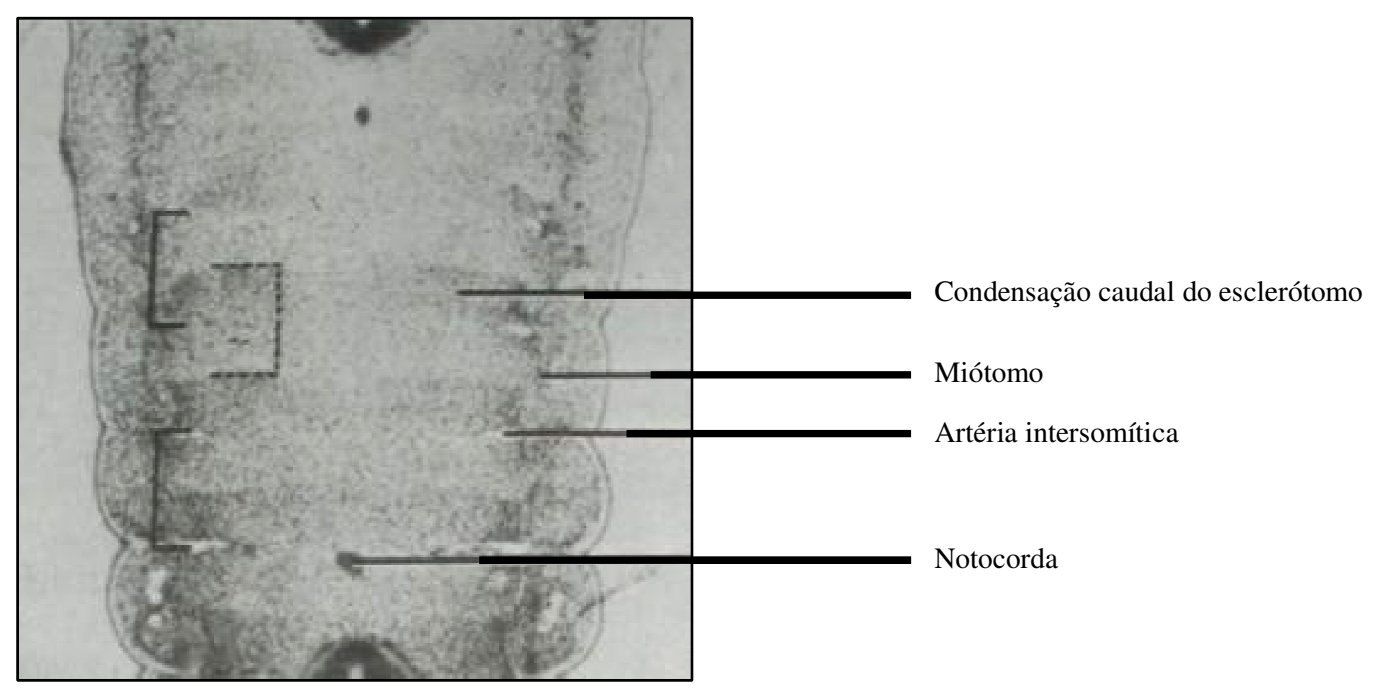

Figura 1. Fotografia demonstrando segmentação do mesênquima dos esclerótomos na região cervical de embrião de ovelha de $12 \mathrm{~mm}$ (aproximadamente 3 semanas). Dentro de cada segmento somítico (marcados com linhas cheias à esquerda) o mesênquima do esclerótomo forma duas subpopulações; a situada mais cranialmente é menos densa que a caudal. A linha descontínua indica o esboço de uma vértebra. (Fonte: Adaptado de NODEN \& LAHUNTA, 1990).

No caso de hemivértebra, parte do corpo da vértebra parece estar ausente (Figura 2), sem sinais de compressão (LeCOUTEUR \& GRANDY, 2004).

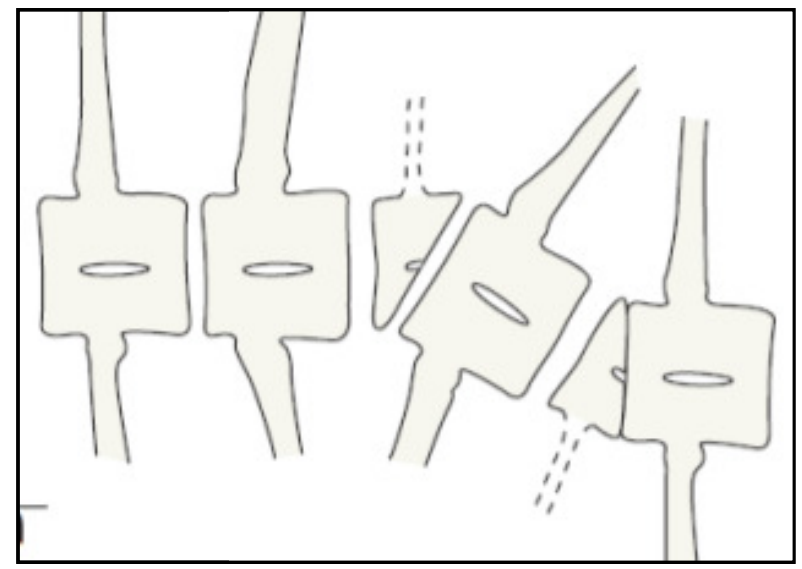

Figura 2. Ilustração esquemática de Hemivértebras. (Fonte: Adaptado de WETWORTH \& STURGES, 2010) 
LEAL, D.S.L. e GOMES, L.A. Hemivértebra em cães e gatos. PUBVET, Londrina, V. 5, N. 32, Ed. 179, Art. 1206, 2011.

\section{Patogenia}

A coluna vertebral tem íntima relação com a medula espinhal, artéria vertebral e nervos espinhais, por esse motivo, a alteração anatômica oriunda de hemivértebra pode causar deformidade no canal vertebral, compressão medular ou de raiz nervosa, anormalidades no suporte sanguíneo, bem como a fragilidade dos discos intervertebrais próximos a vértebra defeituosa (Figura 3) (DONE et al, 1975; BAILEY \& MORGAN, 1992; SEIM III, 2002; LeCOUTEUR \& GRANDY, 2004).

O espaço intervertebral pode se apresentar normal ou mais largo (LeCOUTEUR \& GRANDY, 2004).

Cifose (Figura 4), escoliose e cifoescoliose em graus variados, são as angulações da coluna mais frequentemente observadas em portadores de hemivértebras, raramente se observa lordose (FARROW, 2003).

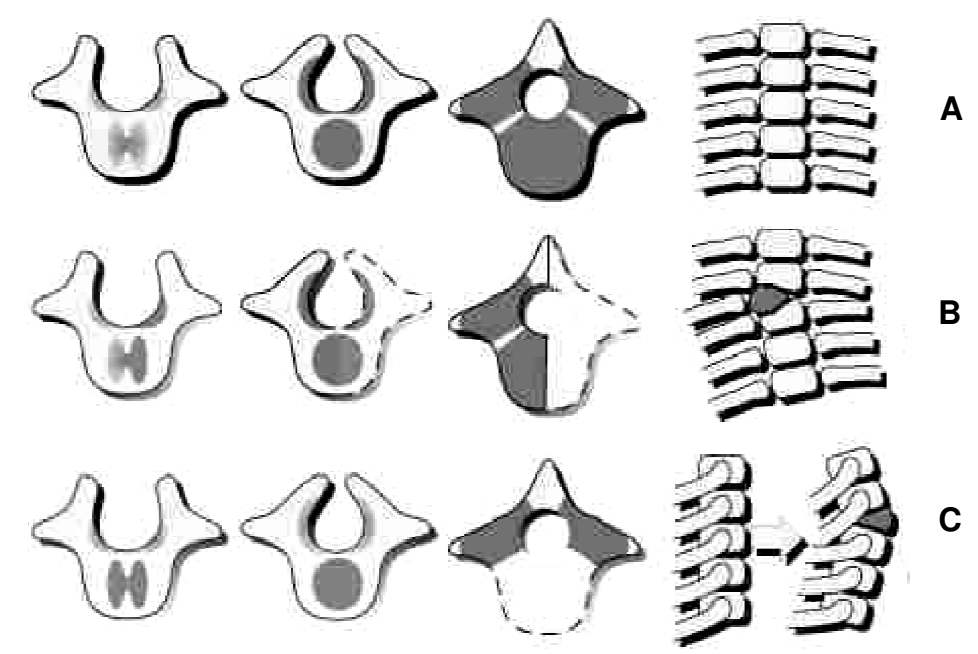

Figura 3. Ilustração esquemática de angulações da coluna vertebral. A: aspecto normal da coluna. B: escoliose causada por presença de hemivértebra lateral. C: Cifose causada por presença de hemivértebra dorsal (Fonte: www.forum.molosy.pl). 
LEAL, D.S.L. e GOMES, L.A. Hemivértebra em cães e gatos. PUBVET, Londrina, V. 5, N. 32, Ed. 179, Art. 1206, 2011.
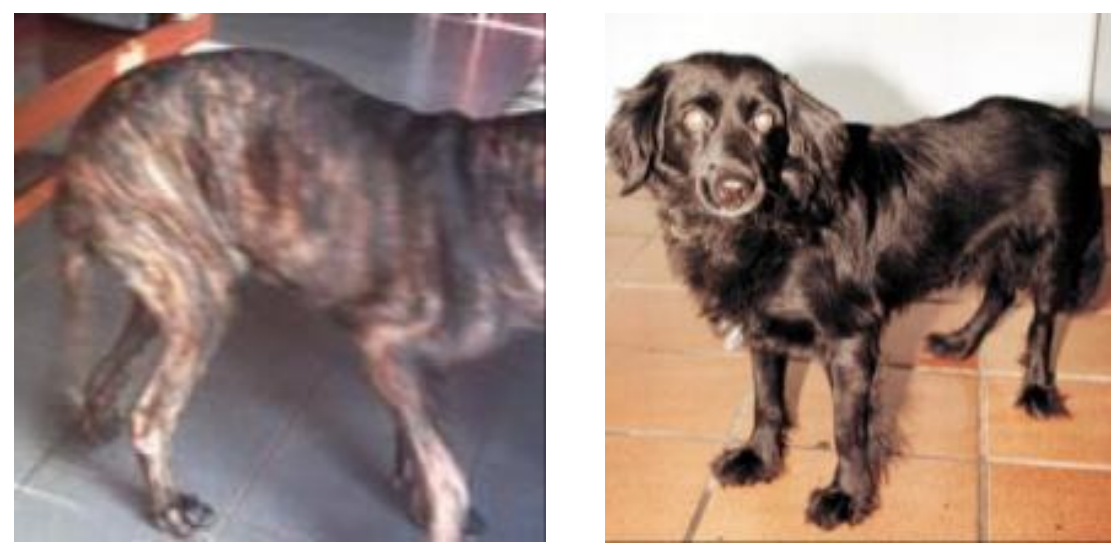

Figura 4. Fotografias demonstrando cães com cifose.

(Fonte: www.vettherapy.com.br).

As angulações tendem a serem progressivas devido ao crescimento do animal, por aumento da compressão vertebral. (DONE et al, 1975; LeCOUTEUR \& GRANDY, 2004).

As vértebras adjacentes costumam ter sua forma alterada de acordo com o defeito encontrado no segmento acometido de forma congênita.

A presença de hemivértebras pode resultar em mielopatia extrínseca. Dentre as doenças hereditárias, as anomalias vertebrais congênitas em geral são a causa principal de mielopatia (LeCOUTEUR \& GRANDY, 2004).

\section{Sinais clínicos}

Os sinais clínicos relacionados com vértebras anômalas não se manifestam na maioria dos casos. Normalmente quando sinais clínicos estão presentes, estes são derivados de traumatismo na medula espinhal na altura da deformidade, e este é secundário a uma instabilidade prévia devido à máformação (LeCOUTEUR \& GRANDY, 2004).

Devido à medula ter funções muito localizadas, um mesmo processo patológico pode resultar em apresentações clínicas bem diferentes, dependendo apenas de sua localização (DONE et al, 1975; LeCOUTEUR \& GRANDY, 2004). 
LEAL, D.S.L. e GOMES, L.A. Hemivértebra em cães e gatos. PUBVET, Londrina, V. 5, N. 32, Ed. 179, Art. 1206, 2011.

Os sinais clínicos incluem cifose, escoliose, cifoescoliose, paraparesia, alterações de propriocepção, alterações nos reflexos tibial cranial, patelar e ciático, hiperestesia no nível da lesão medular, disfunção vesical e dos esfíncteres anal e uretral, ataxia, alterações posturais e durante a marcha (LeCOUTEUR \& GRANDY, 2004). A Tabela1 resume os sinais clínicos encontrados na literatura.

Tabela 1. Sinais clínicos de acordo com alguns autores.

\begin{tabular}{|c|c|c|}
\hline Autor & $\begin{array}{l}\text { Vértebras } \\
\text { anômalas }\end{array}$ & Sinais clínicos \\
\hline LEÓN, 2009 & L1 & $\begin{array}{l}\text { Ataxia } \\
\text { Cruzamento de membros durante a } \\
\text { marcha } \\
\text { Ausência de propriocepção } \\
\text { Não sustentação do peso do corpo sobre } \\
\text { os membros pélvicos } \\
\text { Reflexo patelar diminuído bilateralmente } \\
\text { Reflexo tibial cranial diminuído } \\
\text { Reflexo ciático diminuído } \\
\text { Hiperestesia em região toraco-lombar } \\
\text { Retenção urinária }\end{array}$ \\
\hline $\begin{array}{c}\text { PENHA et al, } \\
2010\end{array}$ & T10 e T11 & $\begin{array}{l}\text { Impotência pélvica funcional bilateral } \\
\text { Propriocepção diminuída em membros } \\
\text { pélvicos } \\
\text { Reflexo patelar diminuído. }\end{array}$ \\
\hline $\begin{array}{c}\text { BRADFORD et } \\
a l, 2008\end{array}$ & T6 e T7 & $\begin{array}{l}\text { Alteração de postura } \\
\text { Cifose } \\
\text { Dificuldade na marcha } \\
\text { Déficits neurológicos em membros } \\
\text { pélvicos } \\
\text { Propriocepção e reflexo de retirada de } \\
\text { membros pélvicos diminuídos }\end{array}$ \\
\hline $\begin{array}{l}\text { HAVLICEK et al, } \\
2008\end{array}$ & T3 & $\begin{array}{l}\text { Ataxia de membros pélvicos com evolução } \\
\text { a paraparesia }\end{array}$ \\
\hline $\begin{array}{l}\text { GRENN \& } \\
\text { LINDO, } 1969\end{array}$ & T5 a T11 & Cifoescoliose \\
\hline $\begin{array}{l}\text { RÄIKKONEN et } \\
\quad a l, 2005\end{array}$ & - & $\begin{array}{l}\text { Escoliose } \\
\text { Paraparesia }\end{array}$ \\
\hline $\begin{array}{l}\text { PELUSO et al, } \\
2009\end{array}$ & - & $\begin{array}{l}\text { Cifose toracolombar } \\
\text { Paraparesia } \\
\text { Ataxia }\end{array}$ \\
\hline
\end{tabular}


LEAL, D.S.L. e GOMES, L.A. Hemivértebra em cães e gatos. PUBVET, Londrina, V. 5, N. 32, Ed. 179, Art. 1206, 2011.

Continuação da tabela 1: Sinais clínicos de acordo com alguns autores.

\begin{tabular}{ccl}
\hline & & $\begin{array}{l}\text { Ausência de resposta à dor profunda em } \\
\text { membros pélvicos } \\
\text { Reflexo flexor e extensor cruzado positivo } \\
\end{array}$ \\
Caminhar espinhal
\end{tabular}

Legenda: $\mathrm{T}=$ Torácica; L= Lombar.

Como as vértebras mais comumente acometidas são as torácicas e as lombares, os sinais neurológicos se restringem mais frequentemente aos membros pélvicos.

\section{Diagnóstico}

a) Exame clínico

Os fatores raça e idade são importantes na suspeita diagnóstica devido à alta incidência hemivértebra em cães braquicefálicos de cauda torcida e, se tratando de doença congênita, podem surgir sinais clínicos ainda durante os primeiros meses de vida, porém em muitos casos os sinais clínicos surgem mais tardiamente, devido ao caráter progressivo de uma possível angulação da coluna, em decorrência do crescimento do animal (GRENN \& LINDO, 1969; BAILEY \& MORGAN, 1992). Atenção especial deve ser dada diante de relato de alteração postural ou na marcha e histórico de trauma na coluna, ainda que o proprietário considere sem importância. Outros fatores a considerar são frequência e atitude com relação à defecação e micção (DONE et al, 1975; LeCOUTEUR \& GRANDY, 2004).

Ao exame físico geral, normalmente não há alterações (GRENN \& LINDO, 1969; DIAZ-FIGUEROA \& SMITH, 2007; LÉON, 2009; PENHA et al, 2010).

Durante o exame neurológico, os sinais clínicos variam de acordo com o local da anomalia e com a gravidade da lesão medular causada pela hemivértebra (LeCOUTEUR \& GRANDY, 2004). O exame neurológico deve ser 
LEAL, D.S.L. e GOMES, L.A. Hemivértebra em cães e gatos. PUBVET, Londrina, V. 5, N. 32, Ed. 179, Art. 1206, 2011.

realizado em local tranquilo e com piso adequado, observando-se o animal em estação e durante a marcha. O animal não deve estar sob efeito de nenhuma medicação sedativa, narcótica, tranquilizante ou analgésica (SEIM III, 2002)

A localização da lesão depende da identificação correta dos cinco os grupos de sinais clínicos observados em todos os animais que manifestem doença que afete a medula espinhal. São eles: (1) depressão ou perda do movimento voluntário; (2) alteração dos reflexos espinhais; (3) alterações no tônus muscular; (4) atrofia muscular e (5) disfunção sensorial. Outros sinais compatíveis são aqueles relacionados à alteração no controle dos esfíncteres uretral e anal. O exame físico também deve ser capaz de identificar a gravidade da lesão (LeCOUTEUR \& GRANDY, 2004).

b) Diagnósticos diferenciais

Envolve outras causas de compressão medular como fratura ou luxação traumática de vértebras, fratura patológica em decorrência de neoplasia vertebral ou osteomielite, doença do disco intervertebral, embolia, meningite e mielopatia degenerativa (LeCOUTEUR \& GRANDY, 2004).

Estas afecções são facilmente descartadas com o uso adequado de exames complementares de imagem e microbiológicos (LeCOUTEUR \& GRANDY, 2004).

c) Diagnóstico por imagem

Um dos maiores desafios no diagnóstico por imagem de pacientes portadores de anomalias vertebrais, é que a maioria dos pacientes apresenta diferentes graus de cifose, lordose e escoliose. A obtenção de imagens é difícil devido a complicações no posicionamento do animal (COSTA \& SAMII, 2010).

A avaliação radiográfica simples da coluna vertebral (Figura 5) é a modalidade de imagem econômica e prontamente disponível para o clínico, sendo uma eficiente ferramenta para a deteç̧ão de hemivértebras. 
LEAL, D.S.L. e GOMES, L.A. Hemivértebra em cães e gatos. PUBVET, Londrina, V. 5, N. 32, Ed. 179, Art. 1206, 2011.

Infelizmente, não oferece a oportunidade de avaliar estruturas neurais (LeCOUTEUR \& GRANDY, 2004; COSTA \& SAMII, 2010).

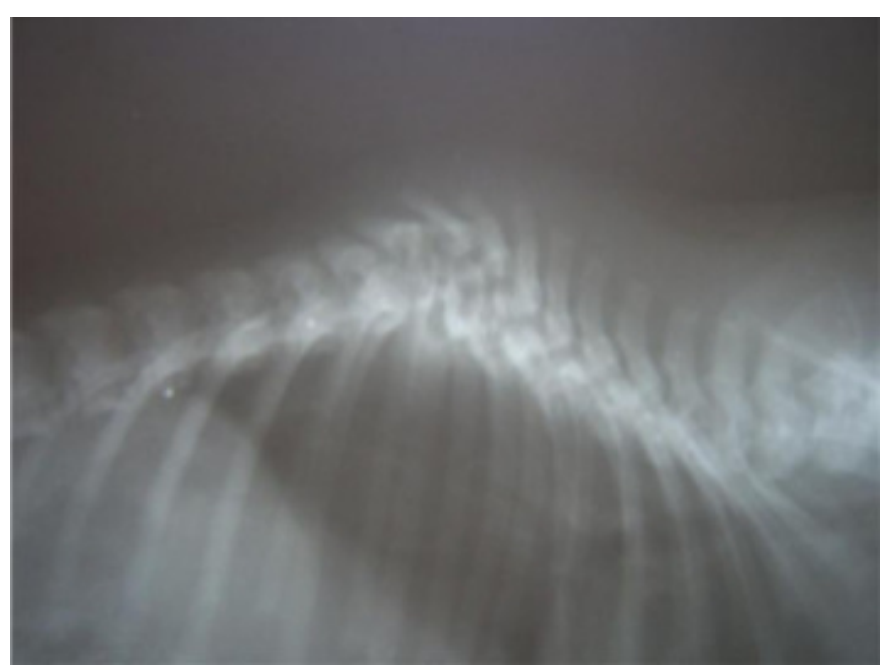

Figura 5. Fotografia demonstrando radiografia simples de segmento da coluna vertebral de cão. Presença de hemivértebra (seta). (Fonte: Adaptado de PELUSO et al, 2009).

Se o paciente apresenta paraparesia, e as imagens radiográficas revelam hemivértebra, pode-se supor que os déficits neurológicos são secundários à má-formação, porém não pode ser comprovado sem um teste de diagnóstico adicional (LeCOUTEUR \& GRANDY, 2004; KNIPE, 2007; COSTA \& SAMII, 2010).

Assim sendo, a mielografia poderá ser realizada após o estudo radiológico como meio de avaliar estruturas neurais. Contraste iodado não iônico é injetado no espaço subaracnóideo para delinear a medula espinhal e identificar qualquer compressão ou distorção da medula espinhal (Figura 6) (COSTA \& SAMII, 2010). 
LEAL, D.S.L. e GOMES, L.A. Hemivértebra em cães e gatos. PUBVET, Londrina, V. 5, N. 32, Ed. 179, Art. 1206, 2011.
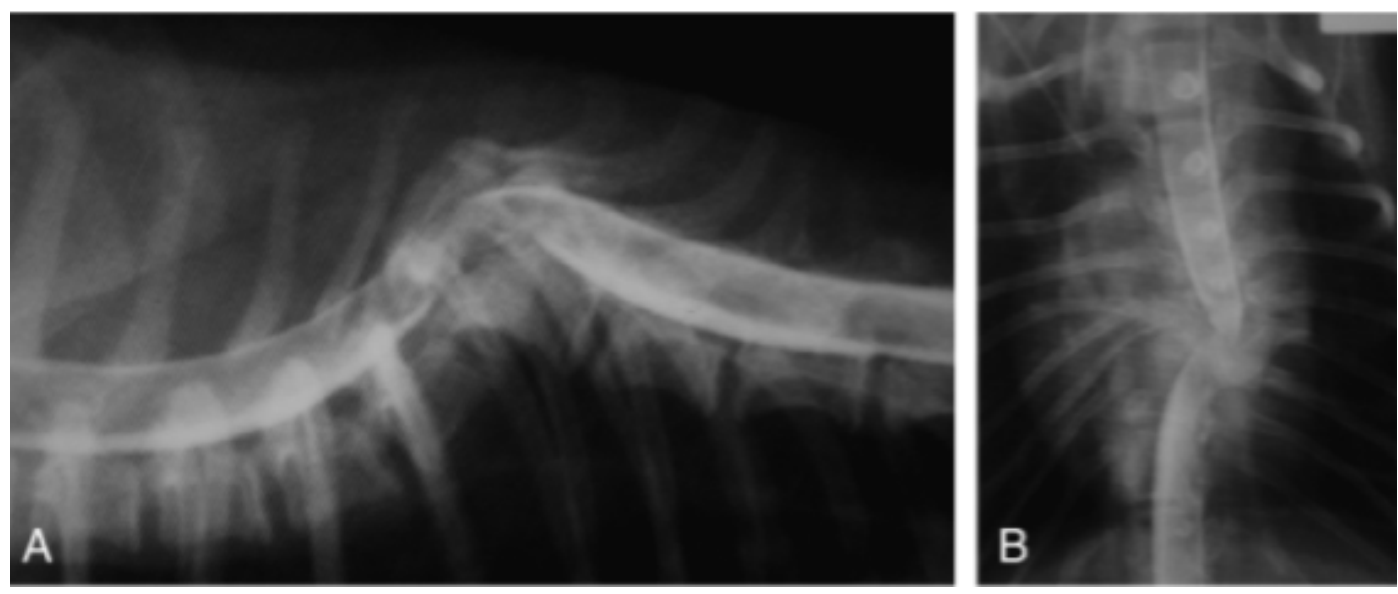

Figura 6. Fotografia demonstrando imagem radiográfica de mielografia em cão: A - projeção lateral direita. B - projeção ventrodorsal. Estenose do canal vertebral (setas) devido à grave cifoescoliose. (Fonte: Adaptado de AIKAWA et al, 2007).

Se possível, o líquido cefalorraquidiano deve ser coletado para análise antes da injeção do material de contraste radiográfico, para descartar doenças infecciosas ou inflamatórias (COSTA \& SAMII, 2010).

Os riscos e complicações da mielografia incluem a introdução inadequada da agulha para a coleta de líquor e as reações do paciente secundárias à injeção de contraste. Danos neurológicos ou transitórios podem resultar da colocação incorreta da agulha. Se realizada com técnica asséptica, o risco de infecção é mínimo (COSTA \& SAMII, 2010).

As vantagens da mielografia são o fato de ser relativamente econômica e de ser um método que avalia a medula espinhal de forma relativamente rápida permitindo inclusive a visualização de lesões extradurais. As desvantagens incluem o fato do exame se tornar difícil ou mesmo impossível devido à anatomia alterada da coluna do animal portador de hemivértebras, e as possíveis complicações que variam de exacerbação transitória dos sinais clínicos de paralisia e até morte (KNIPE, 2007). 
LEAL, D.S.L. e GOMES, L.A. Hemivértebra em cães e gatos. PUBVET, Londrina, V. 5, N. 32, Ed. 179, Art. 1206, 2011.

A tomografia computadorizada é preferencial para melhor definição do osso, especialmente se um processo de estabilização cirúrgica está sendo considerado.

Se déficits neurológicos estiverem presentes, a ressonância magnética (Figura 7) passa a ser o método de diagnóstico por imagem de eleição, para a avaliação da medula espinhal (COSTA \& SAMII, 2010).

Mas, em geral, a tomografia computadorizada oferece resolução espacial superior e é mais adequada para imagens ósseas (COSTA \& SAMII, 2010).
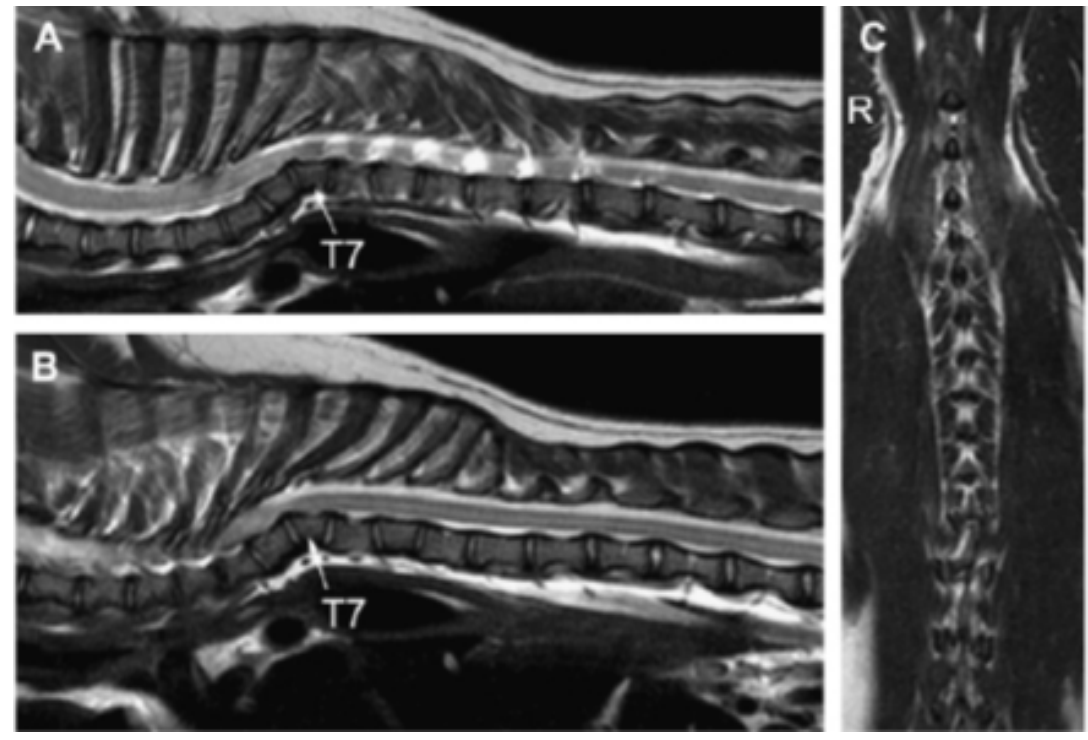

Figura 7. Fotografia demonstrando imagens de ressonânia magnética de Buldogue Francês com lordose e escoliose graves, secundárias da hemivértebra em T7, T8 e T9. A e B, Sagital. C, ventro-dorsal. (Fonte: COSTA \& SAMII, 2010)

\section{Tratamento}

Hemivértebras raramente manifestam sinais clínicos e quando manifestam, já houve uma lesão medular preocupante e possui caráter progressivo devido angulação da coluna resultante da anomalia vertebral, frequentemente causando alterações anatômicas em vértebras adjacentes ao segmento anômalo (LeCOUTEUR \& GRANDY, 2004). 
LEAL, D.S.L. e GOMES, L.A. Hemivértebra em cães e gatos. PUBVET, Londrina, V. 5, N. 32, Ed. 179, Art. 1206, 2011.

A terapia com corticosteróides como a prednisolona é possível, ocorrerá uma melhora inicial do quadro clínico, porém os sinais reaparecem com maior intensidade. Além do fato de que, durante o tempo de espera de resposta ao tratamento com esteróides, podem-se ocorrer danos irreversíveis na medula espinhal (LEÓN, 2009).

Sendo assim, não há tratamento clínico capaz de eliminar ou amenizar definitivamente os sinais clínicos de lesão medular decorrente de hemivértebras, por esse motivo o tratamento cirúrgico é recomendado como solução definitiva. A não correção do defeito ósseo não torna possível a melhora do animal (LEÓN, 2009).

As técnicas cirúrgicas mais comumente empregadas na correção de hemivértebras são: laminectomia dorsal (AIKAWA et al, 2007; HAVLICEK et al, 2008; LEÓN, 2009) e hemilaminectomia (PENHA et al, 2010).

O uso da técnica de laminectomia dorsal torna acessível todas as áreas do canal vertebral e medula espinhal toracolombar, envolvendo a remoção dos processos espinhosos, lâminas dorsais e quantidades variáveis de processos articulares e pedículos de vértebras consecutivas (SEIM III, 2002).

Removem-se os processos espinhosos com osteótomo ou pinça-rugina sem exercer força de torção sobre as vértebras durante as incisões. Removese o osso laminar dorsal com furadeira e brocas. Após a eliminação do osso cortical, a camada medular do osso é visualizada e posterior a essa camada está a outra camada de osso cortical e ainda mais internamente, uma camada periostal translúcida, estas são retiradas com curetas ósseas. O uso da broca deve ser cuidadoso para prevenir o seu escape para o interior do canal vertebral (SEIM III, 2002).

Na laminectomia dorsal modificada, os processos articulares caudais são removidos, porém, a maior parte de cada um dos processos articulares craniais é mantida. Um sub-corte realizado na porção medial dos pedículos confere uma melhor exposição, sem aumentar o risco de fibrose constritiva pósoperatória (SEIM III, 2002). 
LEAL, D.S.L. e GOMES, L.A. Hemivértebra em cães e gatos. PUBVET, Londrina, V. 5, N. 32, Ed. 179, Art. 1206, 2011.

Animais jovens exigem maior cuidado devido à menor resistência do osso à furadeira (LEÓN, 2009).

A técnica de hemilaminectomia está indicada quando há compressão lateral, dorsolateral ou ventrolateral do canal vertebral (SEIM III, 2002).

Removem-se os processos articulares unilateralmente com o uso de rugina. Com pinças de campo, suave tração é aplicada cranialmente ao processo espinhoso da vértebra cranial e caudalmente ao processo espinhoso da vértebra caudal produz alargamento do espaço intervertebral para que a medula seja exposta após a remoção do osso das partes do mesmo lado dos pedículos e das lâminas dorsais das vértebras envolvidas. Com o uso de perfuratriz pneumática e broca procede- se à mini-hemilaminectomia das lâminas rostral e caudal e facetectomia unilateral (SEIM III, 2002).

Se a lesão for restrita à face lateral e ventral do canal espinhal, indica-se pediculectomia (SEIM III, 2002).

A hemilaminectomia é de mais fácil realização que a laminectomia, retira menor quantidade de osso e é mais rápida. Quanto menor quantidade de osso retirada, menor o risco de fibrose constritiva pós-operatória (SEIM III, 2002).

O uso de pinos e polimetimetacrilato pode ser necessário para estabilização da coluna (BAILEY \& MORGAN, 1992; AIKAWA et al, 2007; BRADFORD et al, 2008).

A complicação cirúrgica mais grave é a fratura do corpo vertebral, que poderá ser do tipo cominutiva que é muito difícil de ser corrigida, além de possibilidade de lesão direta na medula durante a fratura (LEÓN, 2009).

Pós-operatório

O pós-operatório inclui fluidoterapia, alívio da dor, estímulo à deambulação em pacientes deambulantes, compressão vesical a cada quatro horas e mudança de decúbito, além de exames neurológicos diários até a alta (AIKAWA et al, 2007).

Fisioterapia é indicada assim que o animal a tolere e a hidroterapia está indicada logo após a retirada dos pontos de pele (AIKAWA et al, 2007). 
LEAL, D.S.L. e GOMES, L.A. Hemivértebra em cães e gatos. PUBVET, Londrina, V. 5, N. 32, Ed. 179, Art. 1206, 2011.

\section{Prognóstico}

O prognóstico é muito variável e está diretamente relacionado ao tempo entre o surgimento dos sinais clínicos de compressão medular e a implantação do tratamento cirúrgico (LEÓN, 2009; PENHA et al, 2010; LeCOUTEUR \& GRANDY, 2004).

A Tabela 2 resume o tempo de recuperação de animais submetidos ao tratamento cirúrgico.

Tabela 2. Tempo entre tratamento cirúrgico e recuperação dos parâmetros neurológicos normais.

\begin{tabular}{|c|c|c|c|}
\hline Autor & Espécie & $\begin{array}{l}\text { Técnica } \\
\text { cirúrgica }\end{array}$ & $\begin{array}{c}\text { Tempo entre tratamento } \\
\text { cirúrgico e recuperação de } \\
\text { parâmetros neurológicos } \\
\text { normais }\end{array}$ \\
\hline $\begin{array}{c}\text { AIKAWA et al, } \\
2007\end{array}$ & Canina & $\begin{array}{c}\text { Laminectomia } \\
\text { dorsal }\end{array}$ & 15 dias \\
\hline $\begin{array}{c}\text { HAVLICEK et al, } \\
2008\end{array}$ & Canina & $\begin{array}{c}\text { Laminectomia } \\
\text { dorsal }\end{array}$ & 30 dias \\
\hline LEÓN, 2009 & Felina & $\begin{array}{c}\text { Laminectomia } \\
\text { dorsal }\end{array}$ & 180 dias \\
\hline $\begin{array}{c}\text { PENHA et al, } \\
2010\end{array}$ & Canina & Hemilaminectomia & $\begin{array}{l}\text { Aproximadamente } 13 \text { dias } \\
\text { (média) }\end{array}$ \\
\hline
\end{tabular}

\section{REFERÊNCIAS}

AIKAWA, T.; KNAZONO, S.; YOSHIGAE, Y.; SHARP, N. J. H. Vertebral stabilization using positively threaded profile pins and polymethylmethacrylate, with or without laminectomy, for spinal canal stenosis and vertebral instability caused by congenital thoracic vertebral anomalies. Veterinary Surgery. v. 36, p. 432-441, 2007

ARAÚJO JÚNIOR, E. P. A; TVARES, R. H.; LIMOEIRO, A.; BARCELOS A. L. L.; NASCIMENTO D. G.; SCHETTINO, L. C. CARELI, L. E. Vertebrectomia posterior isolada no tratamento de deformidades congênitas da coluna vertebral. Coluna/Columna. v.6, p.168-173, 2007.

ARRIAGADA, O. G., CHAHIN, F. A.; PANTOJA, C. S., CHAMORRO, L. M. Resección de hemivértebra con técnica de eggshell en cifoescoliosis congénita: resultados en niños entre uno y siete años. Coluna/Columna, v.8, p.337-343, 2009.

BAILEY, C.S., MORGAN, J.P. Congenital spinal malformations. The Veterinary Clinics of North America Small Animal Practice, v.22, n.4, p.985-1016, 1992. 
BRADFORD, C.; BRONSON, E.; KINTNER, L.; SCHULTZ, D.; MCDONNELL, J. Diagnosis and Attempted Surgical Repair or hemivertebrae in an African Penguin (Sphenicus demersus). Journal of Avian Medicine and Surgery. v.22, p.331-335, 2008.

COSTA, R. C.; SAMII, V. F. Advanced imaging of the spine in small animals. Veterinary Clinics of North America: Small Animal Practice. v. 40, p. 765-790, 2010.

CREMASKI, M.; OLIVEIRA, E. D.; CIARLINI, L D. R. P. Hemivértebra em cão: relato de caso. 10 Simpósio de Pós-Graduação em Ciência Animal e IX Semana de Divulgação Científica do Curso de Medicina Veterinária. Araçatuba/SP, 2009. Disponível em: $<$ http://www.fmvz.unesp.br/revista/volumes/vol17 n1 supl/

Suplemento_v17_n1_supl_35.pdf >. Acesso em: 11 de novembro de 2010.

DIAZ-FIGUEROA, O.; SMITH, M. O. Clinical neurology of ferrets. Veterinary Clinics of North America: Exotic Animal Practice. v. 10, p. 759-773, 2007

DONE, S.H.; DREW, R.A.; ROBINS, G. M.; LANE, J.G. Hemivertebra in the dog: clinical and pathological observations. The Veterinary Record. v.96, n.14. p.313-317, 1975.

DYCE, K. M.; SACK, W. O.; WENSING, C. J. G. Tratado de anatomia veterinária. $3^{a}$ ed. Rio de Janeiro: Guanabara Koogan, 2002.

EVANS, H. E. \& de LAHUNTA, A. Guia para a dissecção do cão. Ossos da coluna vertebral. $5^{a}$ Ed. Rio de Janeiro. Guanabara Koogan, 2000.

FARROW, C. S. Veterinary diagnostic imaging: the dog and cat. Congenital Spinal Malformations, v. 1, Ed. Mosby, p.258-261, 2003

GETTY, R.: SISSON/GROSSMAN. Anatomia dos animais domésticos. $5^{a}$ ed. Rio de Janeiro: Guanabara Koogan, 1986.

GRENN, H.H., LINDO, D.E. Hemivertebrae with severe kypho-scoliosis and accompanying deformities in a dog. Canadian Veterinary Journal, v.10, n.8, p.214-215, 1969.

HAVLICEK, M.; MATHIS, K. R.; BECK, J. A.; ALLAN, G. S. Surgical management of vertebral malformation in a Manx cat. Journal of Feline Medicine and Surgery. v.11, p.514-517, 2009.

KNIPE, M. F. Principles of neurological imaging of exotic animal species. Veterinary Clinics of North America: Exotic Animal Practice. V.10, p. 893-907, 2007.

KRAMER, J.W., SCHIFFER, S.P., SANDE, R.D., WHITENER, E.K. Caracterization of heritable thoracic hemivertebra of the German Shorthaired Pointer. Journal of the American Veterinary Medical Association, v.181, n.8, p.814-815, 1982.

LeCOUTEUR, R. A; GRANDY, J. L. Doenças da medula Espinhal. In: Ettinger S. J., Feldman E. C. editores. Livro texto Tratado de Medicina Interna Veterinária. Doenças do cão e do gato. v.1, 5a Ed. Rio de Janeiro. Guanabara Koogan; 2004. p. 644-94.

LEÓN, A. F. Correción quirúrgica de hemivértebra em um Bulldog. Associacion Latinoamerinana de Neurologia Veterinária/ Neurolatinvet, 2009. Disponível em: <http://www.neurolatinvet.com/casoscli/caso2.htm>. Acesso em: 09 de Novembro de 2010. 
MCMASTER M. J.; OHTSUKA K. The natural history of congenital scoliosis. A study of two hundred and fifty-one patients. Journal Bone and Joint Surgery American. V. 64, p. 128$1147,1982$.

NODEN, D.M.; LAHUNTA, A. Tejidos conectivos y músculos del tronco. In: Embriologia de los animales domésticos. Zaragoza: Acribia, p.153-170, 1990.

PELUSO, E. M.; SILVA, C. E S.; SILVA, G. R.; ARAÚJO, B. M.; FIGUEIREDO, M. L.; SiLVA, A. C.; ESPÍNDOLA, C. R. S.; TUDURY, E. A. Caminhar espinhal associado à hemivértebra em cãorelato de caso. IX Jornada de Ensino pesquisa e Extenção 2009. VI Semana Nacional de Ciência e Tecnologia 2009. UFRPE. Disponível em:

<http://www.eventosufrpe.com.br/jepex2009/cd/resumos/R0527-2.pdf> Acesso em: 11 de novembro de 2010.

PENHA, E. M. et al. Hemivértebras com fusão vertebral em cão- relato de caso. PUBVET. Londrina, v.4, n.21, Ed 126, art. 853, 2010.

RAIKKÖNEN, J.; BIGNERT, A.; MORTENSEN, P.; FERNHOLM, B. Congenital defects in a highly inbred wild wolf population (Canis lupus). Mamaly Biology. v.2, p.65-73, 2006.

SEIM III H. B. Fundamentos de Neurocirurgia. In: Fossum. Tratado de Cirurgia de Pequenos Animais. 2ed. São Paulo: Roca, 2002. p.1139-1158.

SERWIS MOLOSY. Forum, 2010. Disponível em:

$<$ http://www.forum.molosy.pl/showthread.php?p=1099877>. Acesso em: 11 de novembro de 2010.

VETTHERAPY. Fotos, 2010. Disponível em: <www.vettherapy.com.br>. Acesso em: 11 de novembro de 2010.

WESTWORTH, D. R.; STURGES, B. K.; Congenital spinal malformations in small animals. Veterinary Clinics of North America: Small Animal Practice. v. 40, p. 951-981, 2010, 